\title{
The Zulliger-CS in Elderly on Hemodialysis and the Relationship Between External Variables $^{1}$
}

\author{
Viviane Gregoleti \\ Universidade de Passo Fundo, Passo Fundo-RS, Brazil
}

\author{
Silvana Alba Scortegagna \\ Universidade de Passo Fundo, Passo Fundo-RS, Brazil
}

\begin{abstract}
The use of reliable instruments is an ethical condition to exert psychological evaluation. The aim of the study was to investigate the validity of the Zulliger test in the evaluation of elderly with chronic kidney disease (CKD) with focus on cognitive constructs and interpersonal relationships of elderly with Chronic Kidney Disease; and investigate the relationship with external variables. The 60 participants, 30 from the Clinical Group (CG) and 30 from the Non-Clinical Group (NCG), answered a socio-demographic protocol, the Mini-Mental State Examination and the Zulliger test in the Comprehensive System. The CG presented decrease of variables Xu\% $(p=$ $.031, d=.58), \mathrm{R}(p=.002, \mathrm{~d}=.78), \mathrm{Fd}(p=.021, \mathrm{~d}=.65)$ and isolation $(p=.006, \mathrm{~d}=.61)$, rise in X- $\%$, and PHR $>$ GHR. There was a positive association between time since diagnosis and family support ( $\mathrm{rho}=.403, p=.027)$. Findings confirm the relevance of the Zulliger test and family support as a health potentiator.
\end{abstract}

Keywords: projective techniques, psychological assessment, chronic illness, aged

\section{O Zulliger-SC com Idosos em Hemodiálise e a Relação Entre Variáveis Externas}

Resumo: O uso de instrumentos confiáveis é condição ética para o exercício da avaliação psicológica. O objetivo deste estudo foi investigar a utilidade do Zulliger para avaliar idosos com Doença Renal Crônica (DRC), focalizando os construtos cognitivos e de relacionamento interpessoal, bem como verificar a relação com variáveis externas. Os 60 participantes, 30 do Grupo Clínico (GC) e 30 do Grupo Não Clínico (GNC), responderam a um protocolo sociodemográfico, o Miniexame do Estado Mental e o Zulliger no Sistema Compreensivo. O $\mathrm{GC}$ apresentou rebaixamento de $\mathrm{Xu} \%(p=0,031, d=0,58), \mathrm{R}(p=0,002, \mathrm{~d}=0,78), \mathrm{Fd}(p=0,021, d=0,65)$, e de isolamento $(p=0,006$, $d=0,61)$, elevação em X- $\%$ e PHR $>$ GHR. Houve associação positiva entre o tempo de diagnóstico e o suporte familiar $($ rho $=0,403, p=$ 0,027). Os achados ratificam a relevância do Zulliger, apontando o apoio familiar como potencializador de saúde.

Palavras-chave: técnicas projetivas, avaliação psicológica, doenças crônicas, idosos

\section{EI Zulliger-SC con Ancianos en Hemodiálisis y la Relación Entre Variables Externas}

\begin{abstract}
Resumen: El uso de instrumentos seguros es condición ética para el ejercicio de la evaluación psicológica. Se buscó evidenciar la utilidad del Zulliger para evaluar ancianos con enfermedad renal crónica (ERC); y verificar la relación con variables externas. Los 60 participantes, 30 del grupo clínico (GC) y 30 del grupo no clínico (GNC), contestaron un protocolo sociodemográfico, el Mini Examen del Estado Mental y el Zulliger en el Sistema comprensivo. El GC presentó caída de las variables $\mathrm{Xu} \%(p=0,031, d=0,58), \mathrm{R}(p=0,002, d=0,78)$, $\mathrm{Fd}(p=0,021, d=0,65)$ y aislamiento $(p=0,006, d=0,61)$, elevación de X-\% y PHR $>$ GHR. Hubo asociación positiva entre tiempo del diagnostico y apoyo familiar (rho $=0,403, p=0,027$ ). Se ratifica la relevancia del Zulliger y apoyo familiar como potenciador de salud.
\end{abstract}

Palabras clave: técnicas proyectivas, evaluación psicológica, enfermedades crónicas, adultos mayores

Chronic Kidney Disease (CKD) is considered a social and economic problem that advances all over the world, entailing high costs for public health (Levey \& Coresh, 2012). Most older adults on dialysis have low socioeconomic and

\footnotetext{
${ }^{1}$ Paper deriving from the Master's thesis by the author Viviane Gregoleti, under the advice of Silvana Alba Scortegagna, defended in 2015, in the Graduate Program on Human Aging at the Universidade de Passo Fundo. This study was funded by the Coordination for the Improvement of Higher Education Personnel (CAPES).

${ }^{2}$ Correspondence address:

Viviane Gregoleti. Rodovia BR 285, Km 292,7, s/n - São José, Passo Fundo-RS, Brasil., CEP: 99052-900. E-mail: vyvygre@hotmail.com; silvanalba@upf.br
}

education levels (Costa, Alves, Mota, Campos, \& Silva, 2012; Melo, Bezerra, \& Sousa, 2014; Silva, Ribeiro, Rosa, \& Cotta, 2014).

The essential characteristic of the disease is the progressive and irreversible loss of the kidney function, hemodialysis (HD) being one of the most used treatments to maintain the patient's survival (Tetta, Roy, Gatti, \& Cerutti, 2011). HD is an artificial blood filtering process, using a machine that pumps the blood through an extra-body circuit, taking between three and four hours, for which the patient needs to visit the treatment service two to four times per week (Freitas \& Cosmo, 2010). At the same time as the HD 
promotes improvements in some signs of the disease, it can enhance psychosocial problems like stress, anxiety, isolation and depression.

In combination with the problems deriving from the chronic nature of the disease, stress can cause cognitive (Condé et al., 2010; Lopes, Fukushima, Inouye, Pavarini, \& Orlandi, 2014; Sarnak et al., 2013) and interpersonal (Fortes, Bettinelli, Pomatti, Brock, \& Dobne, 2013) difficulties. Other losses, such as the loss of functional capacity and financial losses (Guerra-Guerrero, Sanhueza-Alvarado, \& CaceresEspina, 2012; Lopes et al., 2014; Silva et al., 2014), become even more prominent when family support is lacking (Terra et al., 2010).

Different authors highlight family and social support (Lopes et al., 2014; Prezotto \& Abreu, 2014; Terra et al., 2010; Tezel, Karabulutlu, \& Şahin, 2011) and professional care (Costa et al., 2012; Prezotto \& Abreu, 2014) as essential resources for the patients to cope with the demands deriving from the disease. Considering that the informal support networks are useful in the treatment, Tezel et al. (2011) assessed depression and self-perceived social and family support of HD. The participants were 147 patients, being 84 $(57.1 \%)$ women and $63(42.9 \%)$ men, with a mean age of 46.2 $(S D=14.9)$ years. The authors observed a negative correlation between the depression rates on the BDI $(r=-0.169 ; p<0.05)$ and support from family and friends, assessed through selfreport measures.

Individual variables, such as personality characteristics, can equally contribute to better cope with the disease and comply with the treatment. Pop-Jordanova and Polenakovic (2012) assessed the psychological characteristics of 128 patients in hemodialysis, using the Minnesota Multiphasic Personality Inventory (MMPI) and the Beck Depression Inventory (BDI). As results, they identified that the presence of interpersonal problems, avoidance of friends and relatives and latent aggressiveness and depression can contribute to the emergence of problems in these individuals' social communication.

As observed, the studies basically used psychometric tools. Studies on people in HD assessed by means of selfexpression tools are rare. Only one Brazilian study was found in the literature, by Bellodi, Romão Junior and Jacquemin (1997), in which the Rorschach method was used, but with children. The authors investigated the types of interpersonal relationships, comparing five children in HD with five children in peritoneal dialysis. In the children in HD, the human content responses were significantly less frequent, indicating difficulties to interact and identify themselves with others. The relationship of dependence on the dialysis machine and the hospital team were considered factors that influenced this behavior.

In view of the need to understand how the elderly deal with the physical and/or cognitive disabilities associated with chronic illnesses, the relevance of using the Zulliger in the Comprehensive System (ZCS) is highlighted. The tool assesses the personality and its psychodynamics, combining principles of psychometrics and projection (Villemor-Amaral \& Primi, 2012).
In Brazil, some studies have attempted to demonstrate the importance of the ZCS, using clinical and non-clinical samples. Primi, Muniz and Villemor-Amaral (2012) distinguished among six clinical groups, consisting of alcoholics, schizophrenics, depressive patients, patients with panic disorder, obsessive-compulsive patients, somatoform patients, in a sample of 85 patients and 220 non-patients. The ZCS was able to distinguish among the pathology groups in comparison with the group of non-patients. These findings are relevant, as they show how the ZCS permits the assessment of cognitive, affective, interpersonal relationship and self-image aspects through dislocation and/or projection, differently from the self-reported tests, which further confront people with their symptoms and are more permeable to social desirability. The more individuals denote coherence, logic and flexibility, as evidenced by the manifestation of different cognitive processes, the more they will be able to psychologically adjust to the midst and adapt to the reality (Exner, 2003; Exner \& Sendin, 1999; Villemor-Amaral \& Primi, 2012). That is particularly important when attempting to assess elderly in HD. The way they perceive the reality, translate their perceptions and how they elaborate new concepts can be fundamental to adjust to the demands of the situations that come up in their lives and as a consequence of the disease.

In the $\mathrm{ZCS}$, the cognitive variables are related to information processing, mediation and ideation (VillemorAmaral \& Primi, 2012). The processing refers to how the people approach the experience and includes the variables: (a) Human movement (M), (b) Perseverance (PSV), (c) Synthesized response $(\mathrm{DQ}+)$, (d) Vague responses (DQv). The mediation summarizes how the people translate their perceptions, including the variables: (a) Extended appropriate form $(\mathrm{XA} \%)$, (b) Appropriate form in common areas (WDA\%), (c) Distorted form (X-\%), (d) Blank space response with negative formal quality (S-), (e) Popular response (P), (f) Conventional form $(\mathrm{X}+\%),(\mathrm{g})$ Unusual form $(\mathrm{Xu} \%)$. The ideation is related to what people think of their experiences, including the indicators: (a) Active movement (a), (b) Passive movement (p), (c) Morbid content (MOR), (d) Sum of critical special codes (Sum6), (e) Weighted sum of critical special codes (WSum6), (f) Human movement with distorted formal quality (M-).

If the trends to think illogically, inflexibly or permeated by concerns represent personality difficulties that interfere in the psychological adjustment (Weiner, 2000) and can affect the adjustment to the reality of the elderly in HD, the way they interact with others will also influence the management of the demands deriving from the disease in daily life. Therefore, it is fundamental to discuss the interpersonal relationship, which represents one of the core elements that constitute human conduct, in which conflicts also arise (Exner \& Sendin, 1999). In the ZCS, the interpersonal relationship cluster consists of the following variables: (a) Cooperative movement (COP), (b) Aggressive movement (AG), (c) Good human representation (GHR), (d) Poor human representation (PHR), (e) Active movement (a), passive movement (p), (f) Food responses (Fd), (g) Texture 
responses (SumT), (h) Human responses [Sum $\mathrm{H}=\mathrm{H}+\mathrm{Hd}$ $+(\mathrm{H})+(\mathrm{Hd})]$, (i) Pure human (PureH), (j) Personalized responses (PER), (k) isolation (Isolate). Finally, considering that elderly with $\mathrm{CKD}$ differ from elderly free from the disease in terms of cognitive and interpersonal relationship aspects, the following hypotheses were raised related to the variables of the ZCS:

Hypothesis 1 (H1). The elderly in HD present difficulties in the perceptive adjustment and adaptation of the reality (Condé et al., 2010; Lopes et al., 2014; Sarnak et al., 2013). Therefore, in these patients' ZCS protocols, when compared to the patients free from the disease, the following is expected: (I) Reduction of $\mathrm{X}+\%, \mathrm{R}, \mathrm{P}$ e; (II) Increase in PSV, DQv, X-\%, Xu\%, S-, and MOR.

Hypothesis 2 (H2). The elderly in HD present impaired relationships and interpersonal perception (Fortes et al., 2013; Pop-Jordanova \& Polenakovic, 2012). Therefore, in these patients' ZCS protocols, when compared to the patients free from the disease, the following is expected: (I) Decrease in COP, GHR, pure H and; (II) Increase in PHR, SumT, Fd, PER, AG, isolation.

Hypothesis 3 (H3). As the sociodemographic factors and family support can interfere in the health of elderly people on HD and influence the length of hemodialysis and the time since the diagnosis (Lopes et al., 2014; Prezotto \& Abreu, 2014; Terra et al., 2010; Tezel et al., 2011), a positive association is expected between the length of hemodialysis and family support and a negative association between the length of hemodialysis and education. In view of the above, the objective in this study was to investigate the utility of the ZCS to assess elderly with CKD, focusing on the cognitive and interpersonal relationship constructs, as well as to verify the relation with external variables.

\section{Method}

\section{Participants}

The sample consists of 60 elderly aged 65 years or older, with a mean age of 73.1 years $(S D=5.8)$, living in the state of Rio Grande do Sul-RS. After a non-random selection, the participants were distributed in two groups, clinical (CG) with $\mathrm{CKD}$ and non-clinical (NCG) without $\mathrm{CKD}$, and paired for gender.

The CG consisted of 30 elderly with CKD, with a mean age of 73.9 years $(S D=5.44), 50 \%$ men and $50 \%$ women, with a mean education of 3.43 years $(S D=2.7)$, married $(73.3 \%)$, widowed $(23.3 \%)$ and separated $(3.3 \%)$, $90 \%$ living with relatives. Most of the elderly in the CG presented an income of up to five minimum wages (90\%), were retired farmers $(53.3 \%)$ or housewives $(13.3 \%)$ and all were away from work. These elderly came from two general hospitals and underwent three hemodialysis sessions per week, each session taking four hours, for at least three months. The inclusion criteria were not presenting: (a) change in consciousness due to the effect of drugs that made it impossible to understand the task; (b) hearing deficit that affected communication; and (c) visual disability that interfered in the execution of the tests.

In parallel, the NCG consists of 30 elderly without the disease, 50\% men and 50\% women, who attended community groups at referral and care centers for the elderly. The mean age was 72.33 years $(S D=6.1)$, mean education 4.23 years $(S D$ $=2.8)$, married $(63.3 \%)$, widowed $(33.3 \%)$, separated $(3.3 \%)$, mostly living with relatives $(83.3 \%)$. The majority gained an income of up to five minimum wages $(96.7 \%)$ and was retired farmer (40\%) and housewife (16.7\%). The inclusion criteria were not presenting: (a) history of psychiatric treatment; (b) history of stressful situations deriving from the diagnosis of the disease or of physical disability in the last six months; (c) history of some important loss that caused suffering in the past six months; (d) cognitive deficit; (e) hearing deficit that affected communication; and (f) visual disability that interfered in the execution of the tests.

\section{Instruments}

Protocol of Sociodemographic and Health Characteristics. Elaborated by the researchers, consisting of 16 closed questions, intended to collect information about age, gender, marital situation, profession, education, family support, socioeconomic level, time since diagnosis and hemodialysis; and verify the sample inclusion and exclusion criteria.

Mini-Mental State Examination - MMSE (M.F. Folstein, S.E. Folstein, \& McHugh, 1975). Translated and validated in Brazil by Bertolucci, Brucki, Campacci and Juliano (1994). Intended to assess cognitive aspects and verify the sample inclusion and exclusion criteria. Consists of questions grouped in seven categories, with a total score from 0 to 30 points. The cut-off points from the study by Brucki, Nitrini, Caramelli, Bertolucci and Okamoto (2003) were used: low education (1 to 4 years) - 21 points; mean education ( 4 to 8 years) - 24 points; high education (over 8 years) - 26 points.

Zulliger Comprehensive System - ZCS (VillemorAmaral \& Primi, 2012). Intended to collect information on the mental functioning and personality dynamics. The test consists of three cards with ink blots, one being achromatic, one polychromatic and the third in red and black. As regards the psychometric properties of the tool, Villemor-Amaral, Machado and Noronha (2009) developed a reliability study to verify the precision of the technique. The results were satisfactory as, among the 16 selected indicators, 10 reached high precision ratios, between 0.60 and 0.99 , with significance levels of 0.01 and 0.05 .

\section{Procedure}

Data collection. With the institutions' authorization, the CG was composed by contacting the nurses from the HD sector of two general hospitals. At the same time, the coordinator of the community group was contacted to collect the data from the NCG. All elderly who were willing to participate in the research signed the Free and Informed Consent Form (FICF) and answered the tools individually, during a session that took 
about 50 minutes. The $\mathrm{CG}$ answered the sociodemographic and health protocol and the ZCS in the bed while in HD. The NCG answered the MMSE and all other tools applied in the $\mathrm{CG}$, in the same order, at one of the rooms where the group met. For the sake of greater reliability of the ZCS data, an inter-rater reliability study was developed. After a draft, $25 \%$ of the protocols were forwarded for recoding by an independent judge, followed by the analysis of the Kappa coefficient. Coefficients of 0.87 and higher were obtained for all test variables. Such precision coefficient reveals high reliability (Landis \& Koch, 1977).

Data analysis. The descriptive statistics of the age, education and marital status variables were applied in both groups to describe the sample. The results of the cognitive triad and the interpersonal relationship of the ZCS in the CG and NCG were compared by means of Mann-Whitney's $U$-test, considering coefficients $p<0.05$ as statistically significant. To calculate the effect size, Cohen's $d$ was used, $d=0.20$ being considered a small or weak effect, $d=0.50$ medium or moderate and 0.80 large (Cohen, 1988). The categorical variables were expressed as absolute and relative frequencies. The numerical variables were expressed as means $(M)$ and standard deviations $(S D)$. To check the correlation between the other variables, Spearman's correlation test was applied, considering coefficients $p<.05$ as statistically significant.

\section{Ethical Considerations}

Approval for the study was obtained from the Research Ethics Committee at Universidade de Passo Fundo CEP/ UPF, under opinion 571.126, on March $26^{\text {th }} 2014$. The ethical premises of the Psychologist and National Health Council Resolution 466/12 were complied with.

\section{Results}

In the description of the results, the comparisons will be demonstrated for the scores of the variables related to the cognitive processes; and the interpersonal relationship of the ZCS in the CG and the NCG. Finally, the data for the association between the time since diagnosis in the CG with gender, income and family support variables is presented, as well as with education.

The data shown in Table 1 demonstrate that the cognitive variables that were statistically significant were $\mathrm{Xu} \%$ and $\mathrm{R}$. For these variables, scores in the CG were lower than in the NCG, although not statistically significant. These results indicate two important differences between the groups: (a) mediation difficulties in the CG and trends towards perceptive distortions; (b) low productivity in the CG. Next, the means and standard deviations are presented, as well as the comparison between the CG and the NCG for the interpersonal relationship variables.
Table 1

Comparison between Scores of Variables Related to the Zulliger-CS Cognitive Processes in the Two Groups

\begin{tabular}{|c|c|c|c|}
\hline \multirow{3}{*}{ Variables } & \multicolumn{2}{|c|}{ Group } & \multirow{3}{*}{$d p$} \\
\hline & $\begin{array}{l}\text { Clinical } \\
(n=30)\end{array}$ & $\begin{array}{l}\text { Non Clinical } \\
\quad(n=30)\end{array}$ & \\
\hline & $M(S D)$ & $M(S D)$ & \\
\hline $\mathrm{a}$ & $0.33(0.60)$ & $0.33(0.71)$ & 0.0 .799 \\
\hline $\mathrm{p}$ & $0.30(0.59)$ & $0.13(0.34)$ & 0.35 .281 \\
\hline M & $0.70(0.83)$ & $0.43(0.77)$ & 0.34 .162 \\
\hline MOR & $0.43(0.97)$ & $0.33(0.60)$ & 0.12 .876 \\
\hline Sum6 & $0.53(0.93)$ & $0.53(0.81)$ & 0.0 .736 \\
\hline WSum6 & $1.77(3.46)$ & $1.73(2.71)$ & 0.01 .685 \\
\hline M- & $0.07(0.25)$ & $0.10(0.30)$ & 0.11 .643 \\
\hline XA\% & $\begin{array}{c}67.47 \\
(22.60)\end{array}$ & $73.02(21.10)$ & 0.25 .284 \\
\hline WDA\% & $\begin{array}{c}65.97 \\
(21.69)\end{array}$ & $66.27(23.21)$ & 0.01 .870 \\
\hline$X+\%$ & $\begin{array}{c}56.16 \\
(24.97)\end{array}$ & $52.46(20.41)$ & 0.16 .335 \\
\hline $\mathrm{X}-\%$ & $\begin{array}{c}32.51 \\
(22.60)\end{array}$ & $27.44(20.97)$ & 0.23 .337 \\
\hline $\mathrm{Xu} \%$ & $\begin{array}{c}11.87 \\
(14.12)\end{array}$ & $20.64(16.03)$ & 0.58 .031 \\
\hline S- & $0.40(0.49)$ & $0.37(0.55)$ & 0.06 .672 \\
\hline $\mathrm{P}$ & $1.27(1.01)$ & $1.23(0.85)$ & 0.04 .963 \\
\hline PSV & $0.17(0.46)$ & $0.17(0.37)$ & 0.0 .765 \\
\hline $\mathrm{DQ}^{+}$ & $1.83(1.23)$ & $1.73(1.48)$ & 0.07 .586 \\
\hline DQv & $0.07(0.25)$ & $0.20(0.40)$ & 0.39 .132 \\
\hline $\mathrm{R}$ & $5.67(1.93)$ & $7.20(2.00)$ & 0.78 .002 \\
\hline $\mathrm{F} \%$ & $\begin{array}{c}41.42 \\
(20.28)\end{array}$ & $43.28(18.94)$ & 0.09 .970 \\
\hline FM & $0.73(0.86)$ & $0.90(0.80)$ & 0.20 .341 \\
\hline
\end{tabular}

Note. Legend of ZCS variables: $\mathrm{a}=$ active movement, $\mathrm{p}=$ passive movement, $\mathrm{M}=$ human movement, $\mathrm{MOR}=$ morbid responses, Sum6 $=$ number of critical special codes, WSum $6=$ weighted sum of critical special codes, M- = human movement associated with FQ-, $\mathrm{XA} \%=$ extended appropriate form, $\mathrm{WDA} \%=$ appropriate form in common areas, $\mathrm{X}+\%=$ conventional form, $\mathrm{X}-\%=$ distorted form, $\mathrm{Xu} \%=$ unusual form, $\mathrm{S}-$ = blank space with negative formal quality, $\mathrm{P}=$ popular response, $\mathrm{PSV}=$ perseverance, $\mathrm{DQ}+=$ elaborated development quality, $\mathrm{DQv}=$ immature development quality, $\mathrm{R}=$ number of responses, $\mathrm{F} \%$ = proportion of responses determined by form only, $\mathrm{FM}=$ animal movement. p: probability ratio $<.05$.

According to Table 2, the interpersonal relationship variables that obtained statistically significant coefficients were $\mathrm{Fd}$ and Isolate. The CG obtained lower scores on these variables when compared to the NCG. The lower scores for GHR in relation to PHR are highlighted in the $\mathrm{CG}(\mathrm{GHR}<\mathrm{PHR})$, as well as the higher scores for GHR in relation to PHR in the NCG (GHR $>$ PHR), but without a statistically significant difference. Although the CG does not denote conducts of dependence and social isolation, the presence of distorted perceptions and human representations were identified. 
In the sociodemographic and health characteristics protocol of the CG, family support was referred to as "a lot" $(57.7 \%, n=17)$, "moderate" $(30 \%, n=9)$ or "little" $(13.3 \%, n=4)$. The mean time since the diagnosis of the disease was 116 months (nine years and seven months), the mean time of hemodialysis was 44 months (three years and seven months). Table 3 presents the correlations between external variables related to the time since the diagnosis, which is intended to reflect the time to access the information and the search for medical care, in relation to the education level, and the time since the diagnosis and family support in the CG.

\section{Table 2}

Comparison between Interpersonal Relationship Variables of Zulliger-CS in Both Groups

\begin{tabular}{|c|c|c|c|c|}
\hline \multirow[b]{2}{*}{ Variables } & \multicolumn{2}{|c|}{ Group } & \multirow[b]{2}{*}{$d$} & \multirow[b]{2}{*}{$p$} \\
\hline & $\begin{array}{c}\text { Clinical } \\
(n=30) \\
M(S D)\end{array}$ & $\begin{array}{l}\text { Non Clinical } \\
\quad(n=30) \\
M(S D)\end{array}$ & & \\
\hline $\mathrm{COP}$ & $0.20(0.40)$ & $0.20(0.48)$ & 0.0 & .792 \\
\hline $\mathrm{AG}$ & $0.60(0.67)$ & $0.60(0.85)$ & 0.0 & .691 \\
\hline PER & $1.13(1.45)$ & $1.90(1.91)$ & 0.45 & .100 \\
\hline $\mathrm{Fd}$ & $0.00(0.00)$ & $0.17(0.37)$ & 0.65 & .021 \\
\hline SumT & $0.60(0.72)$ & $0.73(0.98)$ & 0.15 & .794 \\
\hline SumH & $1.83(0.98)$ & $1.47(1.13)$ & 0.34 & .100 \\
\hline (H) & $0.23(0.50)$ & $0.37(0.49)$ & 0.28 & .189 \\
\hline $\mathrm{Hd}$ & $0.40(0.67)$ & $0.13(0.34)$ & 0.51 & .095 \\
\hline (Hd) & $0.00(0.00)$ & $0.00(0.00)$ & 0.0 & 1.000 \\
\hline Pure H & $1.23(0.85)$ & $1.00(0.91)$ & 0.26 & .267 \\
\hline Isolate & $0.90(1.60)$ & $1.93(1.78)$ & 0.61 & .006 \\
\hline GHR & $0.57(0.62)$ & $0.90(1.12)$ & 0.36 & .387 \\
\hline PHR & $0.77(0.72)$ & $0.77(0.67)$ & 0.0 & .955 \\
\hline
\end{tabular}

Note: Legend of ZCS variables: $\mathrm{COP}=$ cooperative movement, $\mathrm{AG}$ = aggressive movement, $\mathrm{PER}=$ personalized responses, $\mathrm{Fd}=$ food, Sum $\mathrm{T}=$ number of texture responses, Sum $\mathrm{H}=$ number of human responses, $(\mathrm{H})=$ full para-humans, $\mathrm{Hd}=$ partial humans, $(\mathrm{Hd})=$ partial para-humans, Pure $\mathrm{H}=$ full humans, Isolate = isolation, $\mathrm{GHR}$ $=$ good representations, $\mathrm{PHR}=$ poor human representations. Values express mean \pm standard deviation. $p$ : probability ratio $<.05$.

In Table 3, a positive, moderate and statistically significant association is observed between the time since the diagnosis and the education level (rho $=0.369, p=$ 0.045). This result suggests that, the longer the time since the diagnosis, the higher the elderly patients' education level. In addition, a positive, moderate and statistically significant association is observed between the time since the diagnosis and family support. As observed, the longer the time since the diagnosis and, consequently, the time of disease, the greater the perceived family support.

Table 3

Correlations between External Variables in Clinical Group: Time since Diagnosis, with Education and Family Support $(n=30)$

\begin{tabular}{llc}
\hline & \multicolumn{2}{c}{ Time since diagnosis } \\
\hline & rho & $p$ \\
Family support & $.403 *$ & .027 \\
Education & $.369^{*}$ & .045 \\
\hline
\end{tabular}

${ }^{*} p=.05$

\section{Discussion}

The aim in this study was to investigate the utility of the ZCS to assess elderly with CKD, focusing on the cognitive and interpersonal relationship constructs, as well as to verify the relation with external variables. The elderly in the CG presented lower scores for the variables $\mathrm{Xu} \%(p=0.031, d$ $=0.58), \mathrm{R}(p=0.002, d=0.78), \mathrm{Fd}(p=0.021, d=0.65)$ and isolation $(p=0.006, d=0.61)$, higher scores for $\mathrm{X}-\%$, and $\mathrm{PHR}>\mathrm{GHR}$ when compared to the NCG. A positive association was found between the time since diagnosis and family support ( $r h o=0.403, p=0.027)$ and between the time since diagnosis and education ( $r h o=0.369, p=0.045)$.

As regards $\mathrm{Xu} \%$, it is important to assess this variable associated with $\mathrm{X}-\%, \mathrm{X}+\%, \mathrm{XA} \%$. The lower scores for $\mathrm{Xu} \%(M=11.87 ; S D=14.12)$ in the $\mathrm{CG}$ are linked to a high frequency of X-\% $(M=32.51 ; S D=22.60)$, differently from what happened to the NCG, in which the variable $\mathrm{Xu} \%(M$ $=20.64 ; S D=16.03)$ is closer to $\mathrm{X}-\%(M=27.44 ; S D=$ 20.97). Based on these indications, it can be assumed that the participants in the CG tend to constitute more inappropriate impressions of the reality when compared to the NCG. This finding confirms background studies that refer cognitive problems in older adults with CKD (Condé et al., 2010; Lopes et al., 2014; Sarnak et al., 2013).

The elderly in the CG also presented lower scores in the $\mathrm{R}(p=0.002, d=0.78)$. This result can derive from the treatment demands that often put a strain on the patients, leaving few perspectives for leisure and interests, and from the job restrictions. The patients in this study underwent three hemodialysis sessions per week and spent four hours on each session (totaling 12 hours per week). In addition, they were absent from their work. This results supports studies that show a productivity decrease, low energy and low motivation in elderly with CKD (Fortes et al., 2013; Freitas \& Cosmo, 2010) and confirms H1 in this study, in that the elderly in HD present difficulties in terms of perceptive adjustment and adjustment of the reality, obtaining lower scores in the number o $\mathrm{R}, \mathrm{X}-\%$ and $\mathrm{Xu} \%$ responses.

A long hemodialysis time is observed, corresponding to 44 months (three years and seven months), similar to other studies (Costa et al., 2012; Lopes et al., 2014; Melo et al., 2014). This factor may have contributed to the low production of answers as, the longer the hemodialysis time, the greater 
the problems in general productivity, disposition for daily, professional and leisure activities and idea production. The routine the hemodialysis treatment imposes can provoke a reduction in physical functioning, arouse feelings of uselessness, impotence and compromise the interpersonal relationships (Guerra-Guerrero et al., 2012; Melo et al., 2014).

As regards the interpersonal relationship, the $\mathrm{CG}$ obtained lower scores for $\mathrm{Fd}(p=0.021, d=0.65)$ and Isolation ( $p=0.006, d=0.61)$ when compared to the NCG. The results of the proportion of GHR:PHR in the CG $(\mathrm{GHR}<$ PHR) differed from the NCG (GHR $>$ PHR). This suggests that the elderly with CKD in this study demonstrated poorer interpersonal relationships, but no trend towards submissive behavior. This information supports the study by Bellodi et al. (1997), in which difficulties to interact with others, decreased interest in gaining new knowledge and disinvestment in the external world were observed in patients in HD, demonstrating a reaction of a machine-dependent life towards the treatment. These results are associated with the rise in the variable $\mathrm{X}-\%$, related to the cognitive process, and partially respond to the initial study hypotheses $\mathrm{H} 1$ and H2. As expected, the GHR dropped and PHR increased in $\mathrm{HD}$, demonstrating impaired relationships and interpersonal perception.

The fact that the elderly with CKD present changes in social functioning, including distancing from friends, from work and from leisure activities, demonstrated in earlier studies (Fortes et al., 2013; Guerra-Guerrero et al., 2012) may be associated with losses in interpersonal relationships. PopJordanova and Polenakovic (2012) evidenced more subtle interpersonal relationships with little involvement in elderly with CKD.

As regards the external variables, a positive association was found between the time since the diagnosis, which demonstrates the access to information and the search for medical care and the education level. The results evidenced a moderate and statistically significant positive correlation (rho $=0.369, p=0.045$ ), suggesting that, the longer the time since the diagnosis of CKD, the higher the education level, not sustaining $\mathrm{H} 3$. In view of the low education and socioeconomic levels among the participants in this and other studies (Costa et al., 2012; Lopes et al., 2014; Melo et al., 2014; Silva et al., 2014), studies involving people with higher education levels and good socioeconomic conditions could try to better understand how the sociodemographic and health variables are related.

When investigating the time since diagnosis with family support, a positive and moderate statistically significant association ( $r h o=0.403, p=0.027$ ) was found, indicating that, the longer the time since diagnosis, the greater the family support. The fact that most elderly with CKD are married may have influenced the family support, as there are daily needs that have to be attended to and the closest people can generally help to perform these tasks (Lopes et al., 2014; Tezel et al., 2011). These findings are in line with the background literature, which emphasizes the importance of the family members' active participation in helping to better cope with the disease, minimize the pain, comply with the treatment and promote a better physical and mental health (Costa et al., 2012; Prezotto \& Abreu, 2014; Terra et al., 2010; Tezel et al., 2011).

Family support seems to contribute to the adoption of a firmer, independent and collaborative attitude towards the adverse situation in the CG, as evidenced in the ZCS for the lowering of $(\mathrm{Fd})$ related to dependence and isolation. These results are in line with studies that appoint family support as an essential resource, considering that family participation can favor better acceptance of the disease and the treatment and minimize the suffering (Costa et al., 2012; Lopes et al., 2014; Prezotto \& Abreu, 2014; Tezel et al., 2011).

Likewise, the perceived care the multidisciplinary health team offers to the elderly seems to enhance the cooperation of the CG, reducing the feelings of helplessness and dependence in these patients. It should be mentioned that the patients with CKD are constantly assessed and take medication regularly. In addition, they are periodically attended by psychologists, physiotherapists and social workers. It is highlighted that this support is important for patients and their loved ones to respond to the treatment. That is a strong reason for the public health policies to establish guidelines for care to elderly with CKD and for their families to be assisted, in view of their direct involvement in the treatment (Costa et al., 2012; Prezotto \& Abreu, 2014; Tezel et al., 2011).

Concerning these study hypotheses, related to difficulties in the perceptive adjustment and adaptation of the reality and to the impaired interpersonal relationship and perception (H1 and $\mathrm{H} 2$ ), these were not fully consolidated. This fact is due to at least two factors: first, to the lower scores in terms of the number of responses, associated with the low education and long time of hemodialysis, which may have interfered in the productive capacity and in the cognitive resources for the production of ideas (Guerra-Guerrero et al., 2012; Melo et al., 2014); and second, to the family support, which in this study influenced the reduction in isolation, dependence and loss of autonomy, as verified in other studies (Costa et al., 2012; Lopes et al., 2014; Prezotto \& Abreu, 2014; Terra et al., 2010; Tezel et al., 2011).

Finally, by responding to the proposed objective, this study evidenced the importance of using the Zulliger to assess elderly in HD, which enhances the power of the tool and strengthens the use of the Comprehensive System, supporting earlier studies (Grazziotin \& Scortegagna, 2016; Primi et al., 2012). Among the results: (a) elderly with CKD present decreased productivity, cognitive problems and impaired interpersonal relationship when compared to the NCG; (b) significant differences were verified between the cognitive $(\mathrm{Xu} \%, \mathrm{X}-\%, \mathrm{R})$ and interpersonal relationship processes $(\mathrm{Fd}$, Isolation, GHR:PHR) in the CG when compared to the NCG. In addition, important results were found for this population segment. Concerning the relation between the disease and external variables, family support was influential for the strengthening of mental health resources, supporting the findings of the ZCS.

These study results should be interpreted with caution, in the light of the limitations. These derive from a nonprobabilistic sample and from one population group, which 
permits neither generalizations nor causal inferences on the relations between the study variables. Nevertheless, the use of a control group - NCG design, the calculation of the Kappa coefficient and the application of quantitative analysis methods increase the reliability of the data and enhance the value of the study, guaranteeing the relevance of the ZCS in the context of CKD.

With regard to its applicability, these study results entail implications for the patients and their relatives; and for the field of psychological assessment. The findings can support health programs that strengthen psychosociological support for the patients, considering that family support is associated with better coping with the disease. In addition, psychological assessment with self-expression methods is highlighted as a valuable procedure, capable of understanding the psychological functioning of elderly with CKD in making decisions about the treatment and in case of doubts or difficulties that may emerge.

In view of the data, the relevance of the theme involving elderly in the public health context, further research is needed, particularly using self-expression methods. These could enhance studies on the variables considered here: cognition, interpersonal relationship; and assess the self-perceived and perceived social support.

\section{References}

Bellodi, P. L., Romão Junior, J. E., \& Jacquemin, A. (1997). Crianças em diálise: Estudo das características de personalidade através de técnicas projetivas [Children on dialysis: Study of the personality characteristics through projective techniques]. Jornal Brasileiro Nefrologia, 19(2), 132-137. Retrieved from http://www.jbn.org.br/ detalhe_artigo.asp?id $=822$

Bertolucci, P. H. F., Brucki, S. M. D., Campacci, S. R., \& Juliano, Y. (1994). O Mini-Exame do Estado Mental em uma população geral: Impacto da escolaridade [The MiniMental State Examination in an outpatient population: Influence of literacy]. Arquivos de Neuropsiquiatria, 52(1), 1-7. doi:10.1590/S0004-282X1994000100001

Brucki, S. M. D., Nitrini, R., Caramelli, P., Bertolucci, P. H. F., \& Okamoto, I. H. (2003). Sugestões para o uso do Mini-Exame do Estado Mental no Brasil [Suggestions for utilization of the Mini-Mental State Examination in Brazil]. Arquivos de Neuropsiquiatria, 61(3-B), 777-781. doi:10.1590/S0004-282X2003000500014

Cohen, J. (1988). Statistical power analysis for the behavioral sciences (2nd ed.). Hillsdale, NJ: Lawrence Erlbaum.

Condé, S. A. L., Fernandes, N., Santos, F. R., Chaouab, A., Mota, M. M. E. P., \& Bastos, M. G. (2010). Declínio cognitivo, depressão e qualidade de vida em pacientes de diferentes estágios da doença renal crônica [Cognitive decline, depression and quality of life in patients at different stages of chronic kidney disease]. Jornal Brasileiro de Nefrologia, 32(3), 242-248. doi:10.1590/ S0101-28002010000300004
Costa, M. S., Alves, M. D. S., Mota, R. M. S., Campos, C. J. G., \& Silva, M. J. (2012). Idosos em hemodiálise: Características sociodemográficas e epidemiológicas [Elderly people under hemodialysis treatment: Epidemiologic and sociodemographic characteristics]. Avances en Enfermería, 30(3), 11-17.

Exner, J. E., Jr. (2003). The Rorschach: A comprehensive system: Vol. 1: Basic foundations and principles of interpretation. New York, NY: Wiley \& Sons.

Exner, J. E., Jr., \& Sendin, C. (1999). Manual de interpretação do Rorschach para o sistema compreensivo [Manual interpretation of the Rorschach comprehensive system]. São Paulo, SP: Casa do Psicólogo.

Folstein, M. F., Folstein, S. E., \& McHugh, P. R. (1975). Mini-mental state: A practical method for grading the cognitive state off patients for the clinician. Journal of Psychiatric Research, 12(3), 189-198. doi:10.1016/00223956(75)90026-6

Fortes, V. L. F., Bettinelli, L. A., Pomatti, D. M., Brock, J., \& Dobne, T. (2013). O itinerário da doença renal crônica: Do prenúncio à descoberta [The chronic renal disease course: from early symptons to discovery]. Revista RENE: Revista da Rede de Enfermagem do Nordeste, 14(3), 531-540. Retrieved from http://www.redalyc.org/ pdf/3240/324027991009.pdf

Freitas, P. P. W., \& Cosmo, M. (2010). Atuação do psicólogo em hemodiálise [Role of the psychologist in hemodialysis]. Revista da SBPH, 13(1), 19-32. Retrieved from http://pepsic.bvsalud.org/scielo.php?script=sci arttext\&pid=S1516-08582010000100003

Grazziotin, J.B.D., \& Scortegagna, S.A. (2016). Mediação no Zulliger: Evidências de validade em amostra de não pacientes [Mediation in Zulliger: Evidence of Validity in Sample of Not Patients]. Psico-USF, 21(1), 63-72. Retrieved from http://www.scielo.br/pdf/pusf/ v21n1/2175-3563-pusf-21-01-00063.pdf

Guerra-Guerrero, V., Sanhueza-Alvarado, O., \& CaceresEspina, M. (2012). Quality of life in people with chronic hemodialysis: Association with sociodemographic, medical-clinical and laboratory variables. Revista LatinoAmericana de Enfermagem, 20(5), 838-846. doi:10.1590/ S0104-11692012000500004

Landis, J. R., \& Koch, G. G. (1977). The measurement of observer agreement for categorical data. Biometrics, 33(1), 159-174.

Levey, A. S., \& Coresh, J. (2012). Chronic kidney disease. Lancet, $\quad 379(9811), \quad$ 165-180. doi:10.1016/S01406736(11)60178-5

Lopes, J. M., Fukushima, R. L. M., Inouye, K., Pavarini, S. C. I., \& Orlandi, F. S. (2014). Qualidade de vida relacionada à saúde de pacientes renais crônicos em diálise [Quality of life related to the health of chronic renal failure patients on dialysis]. Acta Paulista de Enfermagem, 27(3), 230-236. doi:10.1590/1982-0194201400039 
Melo, W. F., Bezerra, A. L. D., \& Sousa, M. N. A. (2014). Perfil epidemiológico dos pacientes com insuficiência renal crônica: Um estudo quantitativo [Epidemiological profile of patients with chronic renal failure: A quantitative study]. Ciência \& Desenvolvimento - Revista Eletrônica da FAINOR, 7(2), 142-156. Retrieved from http://srv02. fainor.com.br/revista/index.php/memorias/article/ viewFile/285/202

Pop-Jordanova, N., \& Polenakovic, M. (2012). Personality profiles and depression in haemodyalisis patients. Prilozi, 33(2), 117-129. Retrieved from http://www.manu.edu.mk/ prilozi/2012_2/10npj.pdf

Primi, R., Muniz, M., \& Villemor-Amaral, A. E. (2012). Validade do Zulliger no sistema compreensivo. [Zulliger validity of the comprehensive system] In A. E. VillemorAmaral \& R. Primi (Orgs.), O teste de Zulliger no sistema compreensivo (ZSC): Forma individual [The Zulliger test the comprehensive system (ZCS): Individual form] (2nd ed., pp. 137-170). São Paulo, SP: Casa do Psicólogo.

Prezotto, K. H., \& Abreu, I. S. (2014). The chronic renal patient and the adherence to hemodialysis treatment. Journal of Nursing UFPE on line, 8(3), 600-605. doi:10.5205/ reuol.5149-42141-1-SM.0803201414

Sarnak, M. J., Tighiouart, H., Scott, T. M., Lou, K. V., Sorensen, E. P., Giang, L. M., .. W Weiner, D. E. (2013). Frequency of and risk factors for poor cognitive performance in hemodialysis patients. Neurology, 80(5), 471-480. doi:10.1212/WNL.0b013e31827f0f7f

Silva, S. T., Ribeiro, R. C. L., Rosa, C. O. B., \& Cotta, R. M. M. (2014). Capacidade cognitiva de indivíduos com doença renal crônica: Relação com características demográficas e clínicas [Cognitive capacity in individuals with chronic kidney disease: Relation to demographic and clinical characteristics]. Jornal Brasileiro de Nefrologia, 36(2), 163-170. doi:10.5935/0101-2800.20140026

Terra, F. S., Costa, A. M. D. D., Figueiredo, E. T., Morais, A. M., Costa, M. D., \& Costa, R. D. (2010). Adesão ao tratamento farmacológico de uso diário de pacientes renais crônicos submetidos à hemodiálise [Adhesion of chronic renal hemodialysis patients to daily pharmacologic treatment]. Revista da Sociedade Brasileira de Clínica Médica, 8(2), 119-124. Retrieved from http://files.bvs.br/ upload/S/1679-1010/2010/v8n2/a006.pdf

Tetta, C., Roy, T., Gatti, E., \& Cerutti, S. (2011). The rise of hemodialysis machines: New technologies in minimizing cardiovascular complications. Expert Review of Cardiovascular Therapy, 9(2), 155-164. doi:10.1586/ erc. 10.194

Tezel, A., Karabulutlu, E., \& Şahin, O. (2011). Depression and perceived social support from family in Turkish patients with chronic renal failure treated by hemodialysis. Journal of Research in Medical Sciences, 16(5), 666673. Retrieved from http://www.ncbi.nlm.nih.gov/pmc/ articles/PMC3214379/
Villemor-Amaral, A. E., Machado, M. A. S., \& Noronha, A. P. P. (2009). O Zulliger no sistema compreensivo: Um estudo de fidedignidade [The Zulliger in the comprehensive system: A reliability study]. Psicologia: Ciência e Profissão, 29(4), 656-671. doi:10.1590/S141498932009000400002

Villemor-Amaral, A. E., \& Primi, R. (2012). O teste de Zulliger no sistema compreensivo (ZSC): Forma individual [Zulliger test in the comprehensive system (ZCS) - Individually] (2nd ed.). São Paulo, SP: Casa do Psicólogo.

Weiner, I. B. (2000). Princípios da interpretação do Rorschach [Principles of Rorschach interpretation] (M. C. V. M. Silva, Trans.). São Paulo, SP: Casa do Psicólogo.

Viviane Gregoleti holds an MSc in Human Aging from Universidade de Passo Fundo.

Silvana Alba Scortegagna is a Professor of the Universidade de Passo Fundo.

Received: May 23, 2015

1st Revision: Oct. 15, 2015

2nd Revision: Dec. 17, 2015

Approved: Feb. 26, 2016

\section{How to cite this article:}

Gregoleti, V., \& Scortegagna, S. A. (2017). The Zulliger-CS in elderly on hemodialysis and the relationship between external variables. Paidéia (Ribeirão Preto), 27(66), 4350. doi: 10.1590/1982-43272766201706 